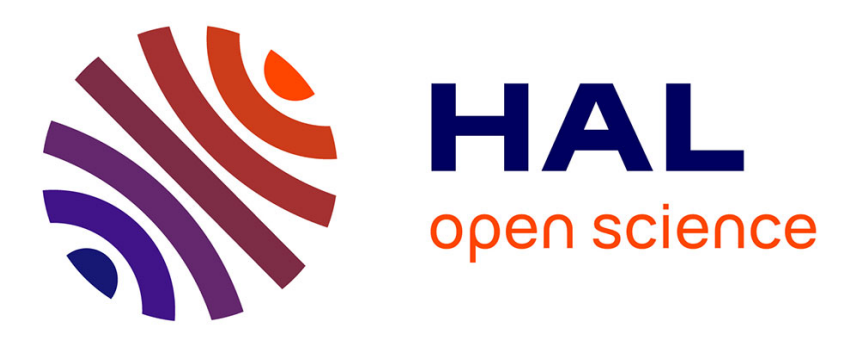

\title{
Influence of the scale and type of processing tool on plasticization of cellulose acetate
}

Thibault Cousin, Christophe Berto, Tatiana Budtova, Joanna Kurek, Patrick

Navard

\section{- To cite this version:}

Thibault Cousin, Christophe Berto, Tatiana Budtova, Joanna Kurek, Patrick Navard. Influence of the scale and type of processing tool on plasticization of cellulose acetate. Polymer Engineering and Science, 2017, 57 (5), pp.563-569. 10.1002/pen.24452 . hal-01414780

HAL Id: hal-01414780

https://hal-mines-paristech.archives-ouvertes.fr/hal-01414780

Submitted on 26 Jul 2017

HAL is a multi-disciplinary open access archive for the deposit and dissemination of scientific research documents, whether they are published or not. The documents may come from teaching and research institutions in France or abroad, or from public or private research centers.
L'archive ouverte pluridisciplinaire HAL, est destinée au dépôt et à la diffusion de documents scientifiques de niveau recherche, publiés ou non, émanant des établissements d'enseignement et de recherche français ou étrangers, des laboratoires publics ou privés. 


\title{
Influence of the Scale and Type of Processing Tool on Plasticization of Cellulose Acetate
}

\author{
Thibault Cousin, ${ }^{1}$ Christophe Berto, ${ }^{1}$ Tatiana Budtova,,${ }^{1}$ Joanna Kurek, ${ }^{2}$ Patrick Navard ${ }^{1}$ \\ ${ }^{1}$ MINES Paris Tech, PSL Research University, CEMEF* - Center for Materials Forming, CNRS UMR 7635, \\ CS 10207 rue Claude Daunesse 06904 Sophia Antipolis Cedex, France \\ ${ }^{2}$ Fraunhofer Institute for Environmental, Safety and Energy Technology (UMSICHT), Osterfelder Straße 3, \\ Oberhausen 46047, Germany
}

Four processing tools (two twin-screw extruders, one being a mini-extruder, and two mixers) were used to prepare plasticized cellulose acetate with $20 \mathrm{wt} \%$ of glycerol triacetate. The goal was to deduce if the scale of the processing tool influences the dispersion of the plasticizer as estimated by the thermal, rheological, and mechanical properties of the obtained materials. The amount of polymer used ranged from $5 \mathrm{~g}$ for mini-extruder to a $10 \mathrm{~kg} / \mathrm{h}$ for pilot-scale extruder. The specific mechanical energy was used to compare the thermal, rheological, and mechanical properties of cellulose acetate obtained with the four processing tools using different processing conditions. The measurement of the glass transition temperature was not able to discriminate the four tools used. Rheology shows differences, not as a function of small or large tools, but in terms of specific mechanical energy. The larger was the tool, the higher were the Young's moduli. This was ascribed to an overall better distribution and dispersion of the plasticizer. However, all variations were small, showing that small laboratory processing machines can prepare thermoplastic compounds with similar properties as pilot scale extruders, at least in what concerns cellulose acetate.

\section{INTRODUCTION}

Various small scale processing machines have been developed for testing new chemicals allowing avoiding large amounts of matter needed to process on conventional pieces of equipment, where at least hundreds of grams of materials are needed $[1,2]$. This is particularly demanded by the pharmaceutical industry where very limited amount of drugs are synthetized in the first development stages [3]. Also, there are more and more new biomass based thermoplastics which are synthesized on a small scale and thus require small processing tools for testing their properties. The obvious question is whether a material produced in small or very small processing equipment is representative of what will be obtained at pilot or even industrial scales. Although these small machines are widely used, there is no clear assessment whether the properties of the obtained material are relevant for a subsequent scaling-up, a question of importance as testing with small quantities of matter may sometimes not be avoided.

Correspondence to: P. Navard; e-mail: patrick.navard@mines-paristech.fr Contract grant sponsor: ADEME; contract grant number: 12-60-C0112. *Member of the European Polysaccharide Network of Excellence (www. enoe.eu).
Scaling-up is fraught with difficulties as many parameters are not easily comparable when using a tool able to process $10 \mathrm{~g}$ or another tailored for $100 \mathrm{~kg}$ to prepare a compound. One of the major differences is the surface-to-volume ratio of the mixing zone that affects friction, heat transfer, and the temperature distribution inside the material being mixed. In most of the published research works, these small scale pieces of equipment are not or not fully compared to conventional larger processing equipment. The few papers giving some efficiency comparisons between machines of different scales are described below. Covas and Costa [4] developed a miniature extrusion line using a micro-extruder able to produce extrudates with a few grams of material. The geometry of the screws was designed using a numerical simulation with the aim of having thermo-mechanical environments comparable to those found in large processing equipment. The efficiency was tested for the dispersion of ethylene propylene diene monomer rubber, in polyamide PA6. It was found that the rubber droplets were bigger in the micro-extruder than in a twin screw extruder, without giving details about the comparison of the conditions used in each tool. Butterfield [5] developed a laboratory mixer (10-40 g) of novel design which mixing performance was assessed using conductive carbon black and compared against three tools, a $0.5 \mathrm{~g}$ mini machine, a $19 \mathrm{~mm}$ co-rotating twin-screw extruder $(0-5 \mathrm{~kg} / \mathrm{h})$ and a $40 \mathrm{~mm}$ co-rotating twin-screw extruder (0-10 kg/h). The comparison with the other machines was not possible because of threshold at which conductivity occurred was not dependent on mixing conditions. Another study [6] described the mixing of PA66 and polyethylene glycol using a twin-screw batch-type DSM miniextruder. The authors do not give any precise comparison with larger processing tools, but note that the influence of the main processing parameters on the dispersed phase size showed trends similar to others already observed, in a previous study, for the same blends prepared using a Haake internal mixer. Maric and Macosko [7] used a cup and rotor mini-mixer, able to process $0.3 \mathrm{~g}$ polymer batches. They compared the efficiency of dispersing particles of polypropy1ene in polystyrene with larger tools and noted that a $16 \mathrm{~mm}$ twin screw is giving different dispersion sizes than the lab scale mixers, and that the dispersion in the cup and rotor mini-mixer was much poorer. The authors noted that adding small steel balls to the cup and rotor was improving the dispersion. Guns et al. [8] developed a mini-extruder with simple screw design, an internal circulation channel, and a production batch size of $5 \mathrm{~cm}^{3}$. They prepared solid dispersions of drugs and compared with the dispersion obtained with a pilot scale extruder $(8 \mathrm{~kg} / \mathrm{h})$. The authors found it was possible to match the process conditions and to produce solid dispersions 
with both types of extruders, although some differences were found between the materials prepared with two machines.

As can be seen from the analysis given above, no study compares processing with different tools providing similar amounts of energy during the mixing. This can be performed when calculating the specific mechanical energy (SME) and taking this parameter into consideration when comparing the different machines, assuming that the systems under consideration will undergo the same morphological changes during processing in the different pieces of equipment.

The objective of this study is thus to tackle two related questions, one is to compare the mixing efficiencies of processing machines with different sizes and second to investigate if the plasticizing of cellulose acetate made with lab-scale mixer or miniextruder is the same as when using large mixing or extrusion machines. These questions will be addressed by mixing cellulose acetate with a classical plasticizer. Cellulose acetate is a thermoplastic polymer made out of chemically-modified renewable resources $[9,10]$. Cellulose acetate was selected because it is a good representative of classical thermoplastics on one hand, and of biomass based polymers on the other hand. The cellulose acetate used in this work has a degree of substitution of 2.5, with a very low crystallinity [11], this low crystal fraction having a melting temperature of about 2258C, very close to its degradation temperature, and with a high glass transition temperature $\mathrm{T}_{\mathrm{g}}$ of about 2008C [12]. This polymer is thus not easily processable without the addition of a plasticizer able to decrease its $T_{\mathrm{g}}$ [13].

Four different blending machines, two extruders and two internal mixers, requiring different amounts of materials from a few grams to tens of kilograms were used. The SME was selected to compare the different machines. The thermal, mechanical and rheological properties of the same plasticized cellulose acetate compounds prepared with these four different tools will be compared.

\section{MATERIALS AND METHODS}

\section{Materials}

Cellulose acetate (CA) was obtained from FKuR Kunststoff $\mathrm{GmbH}$ (Willich, Germany) in powder form with a degree of substitution of 2.5. The combined acetic acid content is between 54.5 and $55.6 \%$. The CA has a density of $1.33 \mathrm{~g} \mathrm{~cm}^{23}$ and the refractive index is 1.47. Glycerol triacetate (GTA) used as plasticizer was purchased from Emery Oleochemicals GmbH (Dfisseldorf, Germany) as technical grade. The GTA has a density of $1.16 \mathrm{~g}$ $\mathrm{cm}^{23}$ and the refractive index is 1.43 . All products were used as received without further purification. Before melt compounding CA was dried for $4 \mathrm{~h}$ at $808 \mathrm{C}$.

\section{Mixing Tools}

In this study, we used four processing tools to prepare plasticized cellulose acetate: "Mini-extruder," "Mixer," "Kneader," and "Extruder" that are described in details below. The amount of polymer needed ranges from $5 \mathrm{~g}$ for mini-extruder to a $10 \mathrm{~kg} / \mathrm{h}$ for pilot-scale extruder. We used two types of compounding tools: two twin-screw extruders and two mixers. The mixers were equipped with rotors and not screws. Using a mixer is a batch process contrary to the extruder which is a continuous process.

All mixtures were composed of $20 \mathrm{wt} \%$ of glycerol triacetate in cellulose acetate as this is a typical composition for plasticizing cellulose acetate. All mixings were carried out at the same set-up temperature of 2008C.

Mini-Extruder. The smallest device used is a Thermo Scientific Haake MiniLab II Micro Compounder called Mini-extruder here. It is designed to process thermoplastic polymers using only an amount of $5 \mathrm{~g}$ or $7 \mathrm{~cm}^{3}$. It is equipped with two counter-rotating screws of $15 \mathrm{~mm}$ diameter. It has a recirculation circuit, allowing the matter to pass several times through the screws to increase the mixing time and potentially improve mixing efficiency. With such recirculation the mini-extruder is transformed into a batch process.

Mixer. The second device in terms of the amount of polymer needed is a Haake Rheomix OS Lab Mixer, called Mixer here, able to mix batches up to $60 \mathrm{~g}$. It is equipped with two counterrotating roller rotors able to produce high shear rates.

Kneader. The Brabender PLASTI-CORDER ${ }^{k}$ Lab Station with Kneader Type 350E, called Kneader here, is a $400 \mathrm{~cm}^{3}$ mixer equipped with two counter-rotating rotors, providing high shear rates. It is designed to compound and test materials formulations.

Extruder. A lab-scale twin-screw extruder TSA EMP 26-40, called Extruder here, was used to prepare compounds. It was used at a feeding rate of $10 \mathrm{~kg} / \mathrm{h}$, with screw speed from 200 to $300 \mathrm{rpm}$, corresponding to average residence times in the order of $80 \mathrm{~s}$.

\section{Injection Molding of Test Specimens}

After compounding by these four processing tools, test specimens for mechanical, and rheological characterizations were prepared by injection molding with a Thermo Scientific Haake MiniJet. It is designed to allow the production of test specimens such as tensile test bars, rheology discs, and so on. with a low amount of material, in the order of $5 \mathrm{~g}$. The temperatures of the heating cylinder and mold were set to 2208C and 958C, respectively. The injection molding was carried under a pressure of 600 bars for $15 \mathrm{~s}$, and a holding pressure of 300 bars was applied for $10 \mathrm{~s}$ to avoid shrinkage.

\section{Characterization}

Oscillatory Rheology. Rheology measurements were performed with an Anton Paar MCR-302 rheometer equipped with parallel plates of diameter $25 \mathrm{~mm}$, with the gap set at $1.5 \mathrm{~mm}$. Frequency sweep tests were done from 100 to $0.1 \mathrm{rad} / \mathrm{s}^{21}$, at $0.1 \%$ strain at 2008C.

Tensile Tests. Uniaxial tensile tests were performed at $0.1 \mathrm{~mm} / \mathrm{s}$ on a Zwick $2.5 \mathrm{kN}$ tensile machine at room temperature. Test bars were dumbbells prepared with the MiniJet injection molding machine, having a gauge length of $40 \mathrm{~mm}$, a width of $5 \mathrm{~mm}$, and a $2 \mathrm{~mm}$ thickness.

Differential Scanning Calorimetry. Differential Scanning Calorimetry (DSC) measurements were performed on a Perkin Elmer Q4000 DSC instrument. Two cycles from 258C to 2308C and back to $258 \mathrm{C}$ were performed at $108 \mathrm{C} / \mathrm{min}$. The glass transition temperatures were measured during the second cycle heating step with a tangent method at half heat capacity change. 
TABLE 1. Speed of the rollers or screw, time of mixing and the corresponding SME for cellulose acetate plasticized with the four different machines (Miniextruder, Mixer, Kneader and Extruder).

\begin{tabular}{|c|c|c|c|c|c|c|c|}
\hline Sample & Speed (rpm) & Time (min) & SME (J/g) & Sample & Speed (rpm) & Time (min) & $\operatorname{SME}(\mathrm{J} / \mathrm{g})$ \\
\hline Mini-extruder-1 & 50 & 5 & 0.97 & Mixer-2 & 100 & 5 & 13.04 \\
\hline Mini-extruder-2 & 100 & 5 & 3.45 & Mixer-3 & 150 & 5 & 19.79 \\
\hline Mini-extruder-3 & 150 & 5 & 6.64 & Mixer-4 & 200 & 5 & 28.20 \\
\hline Mini-extruder-4 & 200 & 5 & 12.54 & Kneader-1 & 50 & 5 & 70.98 \\
\hline Mini-extruder-5 & 50 & 10 & 1.54 & Kneader-2 & 75 & 5 & 78.62 \\
\hline Mini-extruder-6 & 100 & 10 & 6.22 & Kneader-3 & 100 & 5 & 98.68 \\
\hline Mini-extruder-7 & 150 & 10 & 12.97 & Extruder-1 & 200 & $86 \mathrm{~s}^{\mathrm{a}}$ & 13.00 \\
\hline Mini-extruder-8 & 200 & 10 & 19.65 & Extruder-2 & 250 & $82 \mathrm{~s}^{\mathrm{a}}$ & 13.00 \\
\hline Mixer-1 & 50 & 5 & 5.84 & Extruder-3 & 300 & $74 \mathrm{~s}^{\mathrm{a}}$ & 18.00 \\
\hline
\end{tabular}

${ }^{\text {a }}$ The residence time of the polymer in the Extruder was measured by the visual inspection of the appearance of a colored mark added to the polymer.

\section{RESULTS AND DISCUSSION}

\section{Specific Mechanical Energy}

To compare the four processes used in this study, a quantity that characterizes the amount of mixing power applied to the material is needed. This quantity should not depend on the type of the processing tool (i.e., extruder or mixer). The SME meets these requirements. It is defined as a mechanical energy applied to a system per unit of mass:

$$
\text { SME5 } \frac{\text { screw speed }}{\text { mass }}{ }_{0}^{\partial_{\text {mixing time }}} \text { torqueðtpdt }
$$

where the "screw speed" is the rotation speed of the screws of extruders or of rotors of the mixers in rad/s, the "mass" is the mass of the materials introduced in the processing tool in grams and the "torque" is the mechanical torque provided by the motor of the processing tool to the material in Nm. The calculated SME are presented in Table 1 for various screw/rotor speeds and mixing times. Each preparation is named according to the tool used.

From Table 1, two trends can be seen, as expected: (i) the faster the screws/rotors are rotating, the higher the SME is and (ii) the longer the time of mixing, the higher is the mechanical input on the material. According to Eq. 1, the SME should be linearly proportional to the screw speed for a given mixing time. This is not the case for the Mini-extruder as shown on Fig. 1 where the SME is plotted versus screw speed for mixing during $5 \mathrm{~min}$. For example, SME is more than tripled (from 0.97 to $3.45 \mathrm{~J} / \mathrm{g}$ ) when the screw speed is doubled (from 50 to $100 \mathrm{rpm})$. SME versus screw speed for the Mixer is almost linear (Fig. 1). For the bigger tool (Kneader), the SME is decreasing much less than as it could be expected with direct proportionality of SME versus screw speed, with a SME increasing from $70.98 \mathrm{~J} / \mathrm{g}$ at $50 \mathrm{rpm}$ to $98.68 \mathrm{~J} / \mathrm{g}$ at $100 \mathrm{rpm}$ (Fig. 1).

These deviations from the linear proportionality between SME and screw/rotor speeds can come from different reasons. Many papers reported that at a constant mass flow rate, increasing extruder speed is increasing SME or motor energy input, see for example, [14-17]. However, the increase is not necessary following a straight line as it is calculated from the work input from the drive motor into the material being extruded. The work input is not only linked to the mechanical energy dissipated in the material. The SME is a descriptor of molecular changes [18] or dispersion of filler [19] and can be influenced by how these processes are occurring depending of screw speed. It can also be due to other factors as the frictions of motor and screw [14], change of elasticity of the materials [17], or the viscous dissipation of energy during mixing [18]. Examples of nonlinearity can be found in the twin screw extrusion of rice-green gram blends where the SME is increasing faster than linearly, with a stronger nonlinearity with increasing temperature, see Fig. 3 of [14]. When increasing the screw speed, the amount of energy dissipated as heat increases, and so the engine of the processing tool has to provide more power for compensating this heat loss. But a second phenomenon is counter-balancing this first effect. The heat generation may decrease the viscosity of the material. This effect is even more important when the heat conductivity of the material is low, which is the case of polymers [20]. There is then a competition between the energy needed to compensate the heat increase and the energy gained by the decrease of viscosity. This balance is controlled by the capability of the machine to evacuate the heat generated in the materials which are mixed. Table 2 gives estimates of the surface able to evacuate heat and the volume of matter in the four tools.

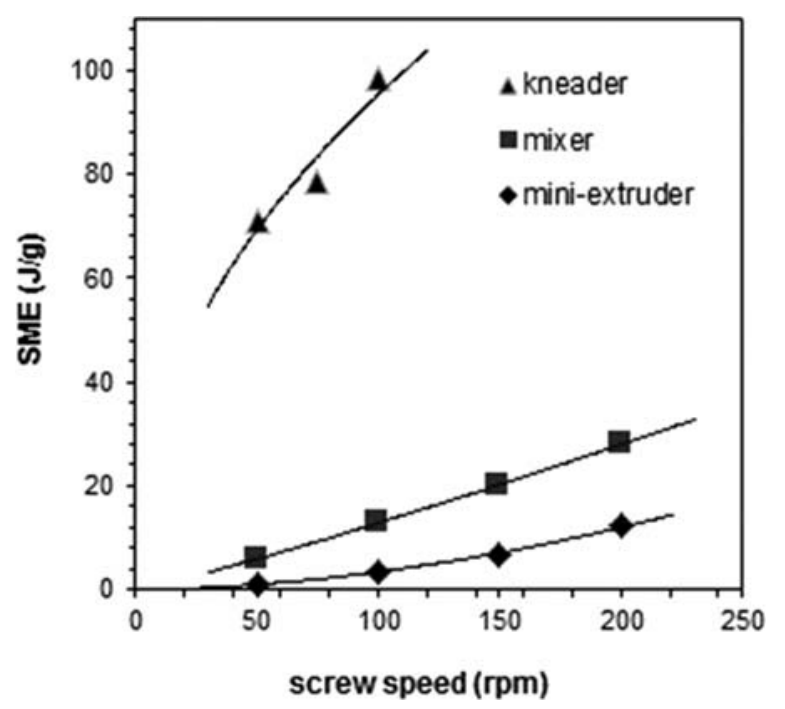

FIG. 1. SME as a function of the screw speed for cellulose acetated plasticized for $5 \mathrm{~min}$ in different processing equipment. Solid lines are the best fits with power-law 1.8 for Mini-extruder, 1.13 for the Mixer, and 0.46 for the Kneader. Data for Extruder are not shown as far as residence time was varied. [Color figure can be viewed at wileyonlinelibrary.com] 
- Mini Extruder 5 min

- Mini Extruder 10 min

$\Delta$ Mixer

XKneader

$\diamond$ Extruder

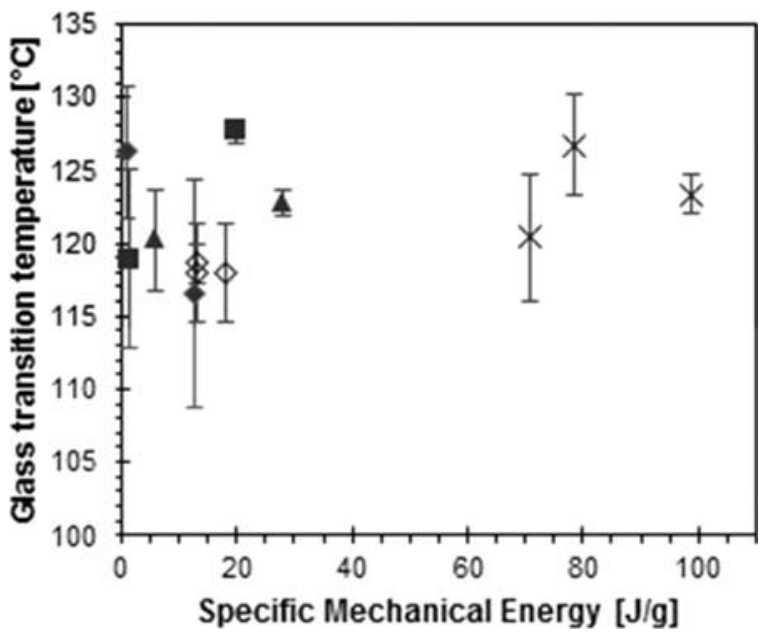

FIG. 2. Glass transition temperature measured by DSC versus SME for cellulose acetate- $20 \mathrm{wt} \%$ glycerol triacetate mixed in the four processing machines. [Color figure can be viewed at wileyonlinelibrary.com]

Table 2 explains why in the machines able to evacuate heat, with a rather high surface to volume ratio (Mini-extruder and Mixer), the SME is increasing faster with screw/rotor speed than predicted by Eq. 1. On the contrary, when the material is heated such as its viscosity is significantly decreased as in the case of the Kneader, the SME is increasing less than predicted by Eq. 1. It can finally be seen that by increasing the size of the batch processing tool, from the Mini-extruder to the $400 \mathrm{~g}$ Kneader, the SME increases for the same screw/rotor speeds. On the contrary, the Extruder shows a SME lower than the Kneader although being the biggest tool of the four. This comes from the short residence times of the matter in the Extruder in comparison with the 5-min mixing time in the other tools.

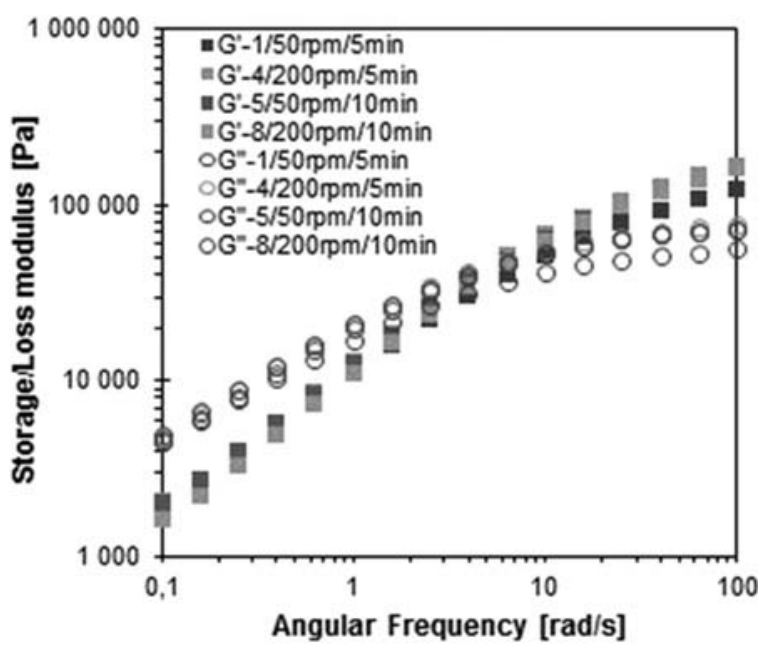

FIG. 3. Storage and loss modulus versus frequency of four compounds prepared with Mini-extruder. [Color figure can be viewed at wileyonlinelibrary. com]
TABLE 2. Estimation of the surface/volume ratio of processing tools.

\begin{tabular}{lcccc}
\hline Tool & Mini-extruder & Mixer & Kneader & Extruder \\
\hline Surface/Volume ratio $\left(\mathrm{mm}^{21}\right)$ & 0.91 & 1.51 & 0.05 & 0.08 \\
\hline
\end{tabular}

Thermal Properties

The thermal properties of the materials, and in particular their glass transition temperature, were measured by DSC. The glass transition $T_{\mathrm{g}}$ is the key parameter to assess the efficiency of a plasticizer as its main role is to decrease $T_{\mathrm{g}}$ [21], allowing the plasticized material to be processed at a lower temperature and increasing its "softness." The glass transition temperatures measured by DSC for cellulose acetate with $20 \mathrm{wt} \%$ glycerol are presented in Fig. 2. For each compound, five randomly selected grinded pellets were tested.

It is known that glycerol triacetate is an efficient plasticizer able to decrease the glass transition temperature of cellulose acetate from 2008C without plasticizer to 110-1308C with 20 wt $\%$ of plasticizer [22]. Considering the experimental error, Fig. 2 shows that there is no correlation between SME obtained in the several processing tools and the glass transition temperature. All materials have a $T_{\mathrm{g}}$ of the same order, around $1218 \mathrm{C}$ even prepared with very different processing machines. The observed variation in $T_{g}$ might be due to a not perfect plasticizer distribution within the polymer. It could have been expected that the higher is the SME, the better would be the mixing. This is not the case. Large error bars are seen at high SME. We could also have expected the Extruder to give the best distribution of plasticizer compared to the small machines. This is not that obvious to conclude, except, maybe, when comparing the error bars of $\mathrm{T}_{\mathrm{g}}$ obtained with the Extruder versus Mini-extruder at $5 \mathrm{mn}$, the latter having large error bars. The only clear trend is seen for both mixers (50 g and $400 \mathrm{~g}$ ones) and the Mini-extruder for the 10-min process, where the dispersion of the DSC results decreases with an increased SME. This means that inside a same batch, the higher the mechanical energy input is, the better are the homogeneity and the distribution of the plasticizer.

\section{Rheological Properties}

Rheology tests were performed for all plasticized cellulose acetate prepared in the four machines. Nonhomogeneous dispersion or distribution of the plasticizer should be detected. The relevant parameters which were analyzed are the storage $\mathrm{G}^{0}$ and loss $\mathrm{G}^{00}$ moduli and the complex viscosity g* (Fig. 3).

The results shown in Fig. 3 are typical for thermoplastic polymers at temperatures above their glass transition temperature. At high frequencies, the storage moduli are higher than the loss moduli meaning that for short range mechanical solicitations the materials have a strong elastic behavior. At low frequencies, the loss moduli are higher than the storage moduli, showing that at long time scale the materials have a strong viscous behavior. Time of mixing and screw speed do not seem to affect the storage modulus within the experimental errors. The loss modulus is, however, $20 \%$ lower in the case of the compound mixed during $5 \mathrm{~min}$ at $50 \mathrm{rpm}$, corresponding to the lowest SME (0.97 $\mathrm{J} / \mathrm{g}$, see Table 1). This could be explained by the very low amount of mechanical energy input, probably not sufficient for 


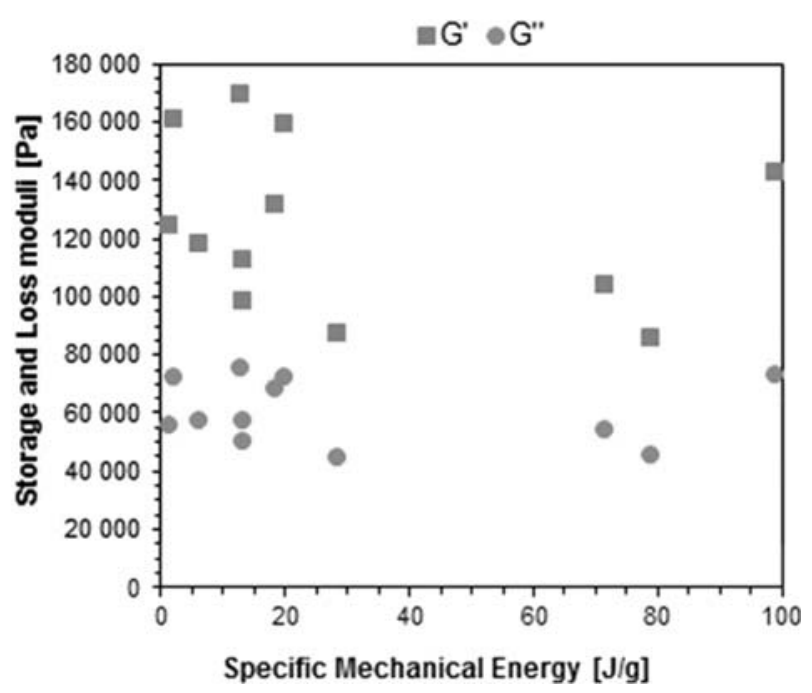

FIG. 4. Storage and loss moduli at $100 \mathrm{rad} / \mathrm{s}$ as a function of SME for plasticized CA prepared with the four different processing tools. [Color figure can be viewed at wileyonlinelibrary.com]

a good distribution of the plasticizer in the compound. All the other compounds prepared with different tools showed the same behavior.

The storage and loss moduli measured at $100 \mathrm{rad} / \mathrm{s}$ and 0.1 $\mathrm{rad} / \mathrm{s}$ as a function of the SME for all compounds prepared with the different tools are displayed on Figs. 4 and 5, respectively. Figure $4(100 \mathrm{rad} / \mathrm{s})$ shows that the storage modulus at $100 \mathrm{rad} / \mathrm{s}$ ranges from 85 to $170 \mathrm{kPa}$ whereas the loss modulus ranges between 45 and $95 \mathrm{kPa}$. Figure $5(0.1 \mathrm{rad} / \mathrm{s})$ shows that the storage modulus ranges from 950 to 2,000 $\mathrm{Pa}$ and the loss modulus is between 2,750 and 5,000 Pa. At high frequency, short chain segments are probed. The large scattering and the lack of correlation with the SME of the elastic response, in particular at low SME, is reminiscent of what can be seen on Fig. 2, where the glass transition temperature is plotted against SME. Both the high frequency moduli and $T_{g}$ are very sensitive to the local

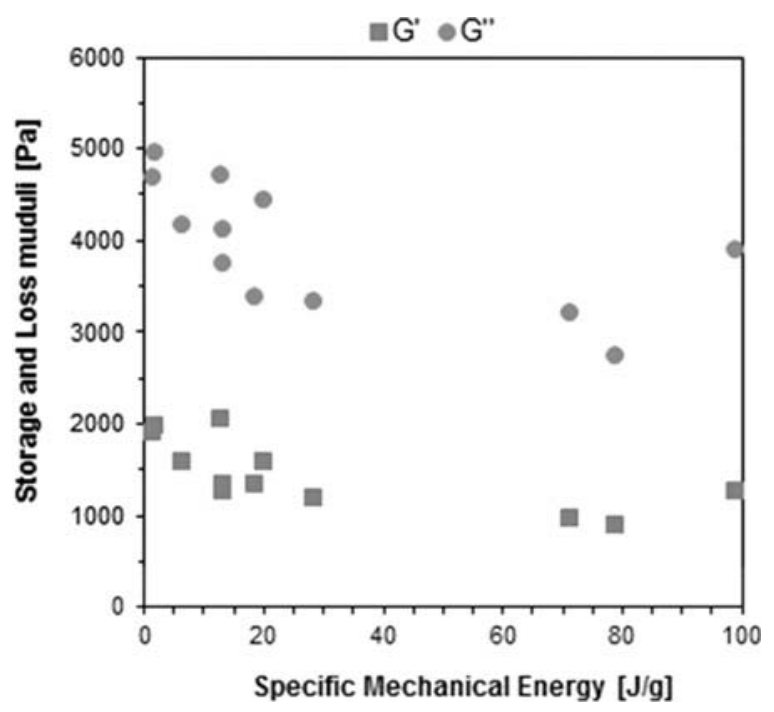

FIG. 5. Storage and loss moduli at $0.1 \mathrm{rad} / \mathrm{s}$ as a function of the SME for plasticized cellulose acetate prepared with the four different processing tools. [Color figure can be viewed at wileyonlinelibrary.com]

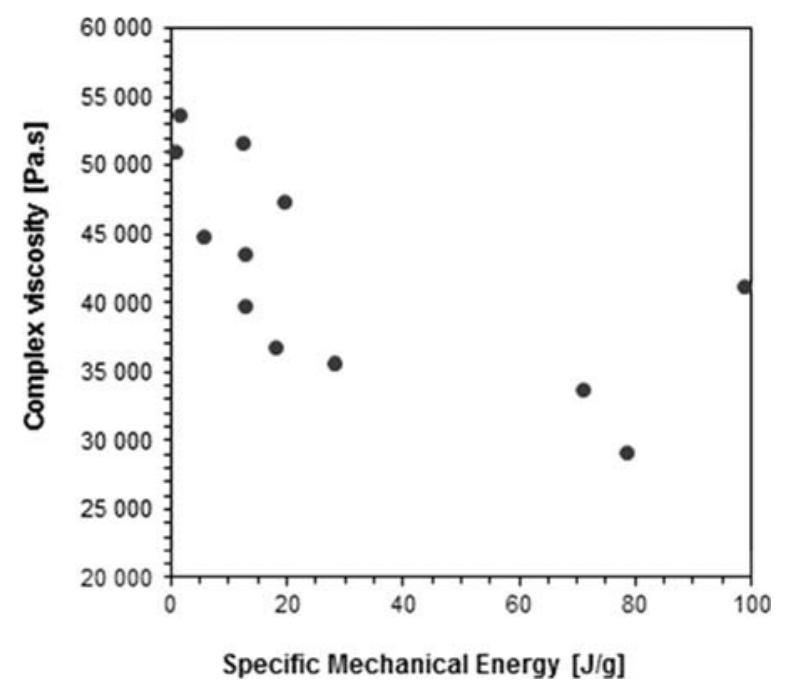

FIG. 6. Complex viscosity measured at $0.1 \mathrm{rad} / \mathrm{s}$ as a function of the SME. [Color figure can be viewed at wileyonlinelibrary.com]

chain environment. Their scattering is the sign that there is a rather large variation in the way the plasticizer interacts locally with polymer chains. What is noticeable is that if such variations can be understood when probing the material by DSC (where a few mg of sample are tested), this is more astonishing in the case of rheology where the size of the sample is about $1 \mathrm{~g}$. Clearly, there is long range variation of the plasticizer concentration.

As soon as the whole polymer chain is concerned, as it is the case at low frequencies, shown on Fig. 5, the scattering is much less pronounced. A decrease of both moduli with SME increase can be seen in Fig. 5. Another way to see this decrease is to plot the complex viscosity. The complex viscosity of the materials as a function of frequency, not shown, shows a classical nonlinear behavior for all mixing cases. The complex viscosity measured at $0.1 \mathrm{rad} / \mathrm{s}$ is plotted as a function of the SME on Fig. 6. Higher SME leads to viscosity decrease. The most probable explanation is that upon increasing SME, polymer may degrade thus decreasing its viscosity.

\section{Mechanical Properties}

Uniaxial tensile tests were performed after injection of standard test specimens. The plasticized cellulose acetate has a brittle behavior, that is, specimens break before yielding, with a strain at break between 8 and 10\% and a stress at break of about $70 \mathrm{MPa}$. Two main properties, Young's modulus and the strain at break, were extracted from the stress-strain curves to compare the different processes.

Young's moduli of the materials prepared with different processing conditions and machines are presented in Fig. 7. Overall, all Young's moduli are of the same order, around 1.75 GPa. The amount of SME or the processing tool do not strongly affect the Young's modulus. However, the two larger tools (Kneader and Extruder) were able to produce material with a slightly higher Young's modulus, around $1.9 \mathrm{GPa}$. This is a rather interesting result, quite unexpected regarding the previous results, which did not show a clear advantage of using large machines. The Young's modulus is sensitive to the good mixing 


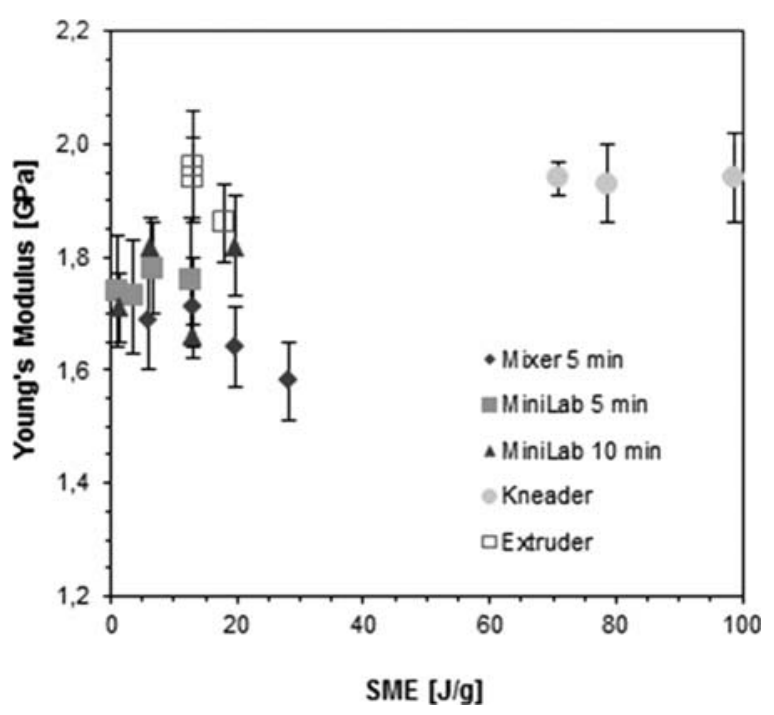

FIG. 7. Young's modulus as a function of the SME. [Color figure can be viewed at wileyonlinelibrary.com]

(good dispersion and distribution of plasticizer). Larger machines seem to better homogenize the mixtures.

The strain at break is another important mechanical property that can be influenced by the efficiency of a plasticizer and the quality of mixing. Strain at break for all samples prepared is shown on Fig. 8. Neither the SME nor the processing tool seem to affect the strain at break of the compounds, remaining around 9-10\%.

\section{CONCLUSIONS}

Cellulose acetate was plasticized with four different tools, from a very small scale (5 g) to a semi-industrial scale (10 kg/ h). The influence of the processing tool on thermal, rheological and mechanical properties of cellulose acetate was investigated. The SME was used to compare the processing tools and different processing conditions. The measurement of the glass transition temperature was not able to discriminate the four tools used, most probably because if any variation existed, it was

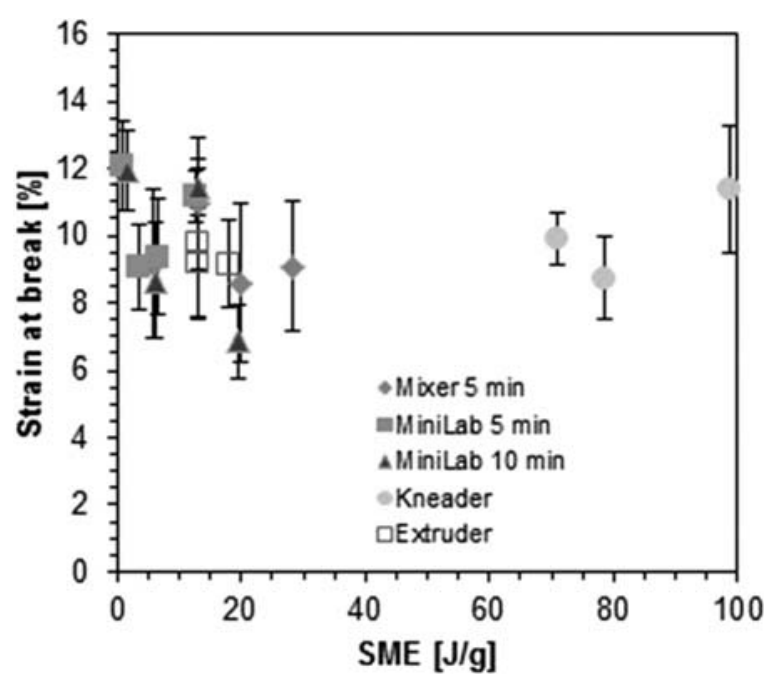

FIG. 8. Strain at break as a function of the SME. [Color figure can be viewed at wileyonlinelibrary.com] hidden inside the errors made by sampling very low amounts of materials and by the low precision of the determination of $T_{g}$. Rheology showed differences, not as a function of small or large tools, but in terms of SME. The higher was the SME, the lower was the viscosity, a phenomenon ascribed to a slight decrease of molar mass. However, this did not affect the elastic modulus of the materials as SME was not the discriminating factor. The larger was the tool, the higher were the Young's moduli. This was ascribed to an overall better distribution and dispersion of the plasticizer. However, all the variations mentioned above are small, almost within the experimental error except viscosity. This study is thus proving that small laboratory processing machines can prepare thermoplastic compounds with similar properties than pilot scale extruders, a least in what concerns cellulose acetate and the conditions used. This brings some confidence when using small equipment if the needed ingredients are only obtainable in small quantities at the early stages of the development process.

\section{ACKNOWLEDGMENTS}

This work was performed under the framework "Hemicell" project of the European Commission WoodWisdom-Net1 research program.

\section{REFERENCES}

1. B. Ly, W. Thielemans, A. Dufresne, D. Chaussy, and M.N. Belgacem, Compos. Sci. Technol., 68, 3193 (2008).

2. O. Breuer, U. Sundararaj, and R.W. Toogood, Polym. Eng. Sci., 44, 868 (2004).

3. A. Almeida, S. Possemiers, M.N. Boone, T. De Beer, T. Quinten, L. Van Hoorebeke, J.P. Remon, and C. Vervaet, Eur. J. Pharm. Biopharm., 77, 297 (2011).

4. J.A. Covas and P. Costa, Polym. Test., 23, 763 (2004).

5. R.C. Butterfield, "Development of a new minimixer that can duplicate mixing which occurs in a large twin screw extruder," PhD dissertation, School of Engineering, Design and Technology, University of Bradford, UK (2009)

6. J. Leblanc, F. Pla, M. Mercier, and P. Pitiot, Chem. Eng. Sci., 64, 1918 (2009).

7. M. Maric and C. Macosko, Polym. Eng. Sci., 41, 118 (2001).

8. S. Guns, V. Mathot, J.A. Martens, G. Van den Mooter, Eur. J. Pharm. Biopharm., 81, 674 (2012).

9. K. Edgar, C.M. Buchanan, J.S. Debenham, P.A. Rundquist, B.D. Seiler, M.C. Shelton, D. Tindall, Prog. Polym. Sci., 26, 1605 (2001).

10. S. Fischer, K. Thfimmler, B. Volkert, K. Hettrich, I. Schmidt, K. Fischer, Macromol. Symp., 262, (2008).

11. P. Zugenmaier, Macromol. Symp., 208, 81 (2004).

12. K. Kamide, S. Masatoshi, Polym. J., 17, 919 (1985).

13. H. Warth, R. Mellhaupt, J. Schøtzle, J. Appl. Polym. Sci., 64, 231 (1997).

14. S. Bhattacharya, J. Food Eng., 32, 83 (1997).

15. Y.K. Chang, F. Martinez-Bustos, T.S. Park, J.L. Korini, Braz. J. Chem. Eng., 16, 285 (1999).

16. G. Della Valle, A. Zozlowski, P. Colonna, and J.P. Tayeb, Lebensm. Wiss. Technol., 22, 279 (1989) 
17. S.I. Fletcher, P. Richmond, and A.C. Smith, J. Food Eng., 4, 291 (1985).

18. S. Godavarti and M.V. Karwe, J. Agric. Eng. Res., 67, 277 (1997).

19. T. Domenech, E. Peuvrel-Disdier, B. Vergnes, Compos. Sci. Technol., 75, 7 (2013).

20. C.L. Choy, Polymer, 18, 984 (1977).

21. M. Vieira, M. Gurgel Adeodato, M. Altenhofen da Silva, L. Oliveira dos Santos, and M. Masumi Beppu, Eur. Polym. J., 47, 254 (2011).
22. S. Zepnik, T. Hildebrand, S. Kabasci, H.J. Radusch, and T.S. Wodke, "Cellulose Acetate for Thermoplastic Foam Extrusion," in Cellulose - Biomass Conversion. Theo van de Ven and John Kadla, Eds., InTech, (2013).

23. L. Chen, X.-J. Pang, and Z.-L. Yu, Mater. Sci. Eng., 457, 287 (2007).

24. B. Lin, U. Sundararaj, and P. PGtschke, Macromol. Mater. Eng., 291, 227 (2006).

25. B. Mayoral, J. Lopes, and T. McNally, Macromol. Mater. Eng., 299, 607 (2014). 
AQ1: Please check whether affiliations are OK as typeset.

AQ2: Please check whether grant information is $\mathrm{OK}$ as typeset.

AQ3: Please check whether the footnote is OK as typeset.

AQ4: Please check whether heads and subheads are OK as typeset.

AQ5: Please note that references are not sequentially cited in text. Hence renumbering has been done. Please check.

AQ6: Please provide page number for Ref. 10.

AQ7: Please check whether Ref. 22 is OK as typeset.

AQ8: Please provide location for Ref. 22.

AQ9: Please note that there is no mention of References [23, 24, and 25] in the text. Please check.

AQ10: Please confirm that given names (red) and surnames/family names (green) have been identified correctly.

Please confirm that the funding sponsor list below was correctly extracted from your article: that it includes all funders and that the text has been matched to the correct FundRef Registry organization names. If a name was not found in the FundRef registry, it may be not the canonical name form or it may be a program name rather than an organization name or it may be an organization not yet included in FundRef Registry. If you know of another name form or a parent organization name for a not found item on this list below, please share that information.

\begin{tabular}{|l|l|l|l|}
\hline FundRef name & $\begin{array}{l}\text { FundRef Organization } \\
\text { Name (Country) }\end{array}$ & FundRef DOI & Grant IDs \\
\hline ADEME & $\begin{array}{l}\text { Agence de l'Environnement et } \\
\text { de la Maetrise de l'Energie }\end{array}$ & $10.13039 / 501100003031$ & $12-60-$ C0112 \\
\hline
\end{tabular}

